\title{
Prevalence of brucellosis in Kohgiluyeh and Boyer Ahmad Province in 2017
}

\author{
Sayyedzaker Saeedinejad ${ }^{1}$, Mohammadsaeed Mirzaee $^{2}$, Zafar Parisaee ${ }^{3}$, Arash Khalilii $^{4}$ Akvan Paymard ${ }^{5}$
}

\begin{abstract}
Introduction: Brucellosis is a common infectious disease between humans and livestock, which can cause severe economic and health damage to the community. Considering the importance of this study, the aim of this study was to determine the prevalence of brucellosis in Kohgiluyeh and Boyer Ahmad Province in 2017.

Materials and Methods: This retrospective cohort study was conducted to determine the rate and causes of brucellosis in Kohgiluyeh and Boyer Ahmad province in 1396. Sampling was done by census. Information about 300 patients with brucellosis, collected from April to July 1996, was collected. In order to collect data from a researcher-made list, data collection for brucellosis patients was used. Descriptive statistics and SPSS 21 series software were used to analyze the data.

Results: 17 cases had negative test. The highest number of occurrences in 2016 was 143 cases and the highest occurrence was 171 in the spring. Boyer Ahmad city has the highest rate with 107 cases and Bahmei city with the least amount of brucellosis in 9 cases. 360 people were from rural population. The group of livestock breeders with 147 cases was the most affected and the military group with the least one was the least.

Conclusion: By planning properly and timely, you can prevent the disease, complications and dangers of brucellosis.
\end{abstract}

Keywords: brucellosis, gram negative basil, prevention

\section{INTRODUCTION}

Brucellosis is a common disease between humans and animals and appears in acute, acute and chronic forms (1). The prevalence of this disease depends on the number of livestock and the absence of complete animal vaccination (2). Among the various causes of brucellosis, the most common cause of the bacterial pathogenicity of the coccobacilli is germicide of the invasive Brucella National Tenissi (3). Communication and consumption of animals such as sheep, dogs, camels and cows, dolphins and eel can provide conditions for the disease in humans (4). Brucellosis can even survive in dairy products for a long time, causing contamination and disease in humans (5). Human involvement with brucellosis is very important both in terms of health and economics (6).

Due to the inaccessibility of accurate data on the extent of infection, there is no accurate statistics on the distribution of this disease in the world (7). In Iran, the number of cases of brucellosis has been estimated to be around $25 \%$ per 100,000 , which is declining annually (8). Brucellosis is present in various parts of the world, especially in the Mediterranean, the Middle East, the Arabian Peninsula, Central and South America, Asia and Africa (9). In countries like the United States, the disease is considered a work hazard (10). The most frequent season that this disease may develop is spring and summer, and it is seen in rural areas more than urban areas (11). In Iran, there are concerns about the disease in the western regions (12). Kohgiluyeh and Boyer Ahmad province, in terms of geographical location and its

\footnotetext{
1 Assistance Professor of Infectious Disease MD Mph, Clinical Research Development Unit Beheshti Hospital, Yasuj University of Medical Sciences, Yasuj, Iran

2 Master of Medical Surgical Nursing, Saveh University of Medical Sciences, Saveh, Iran

3 Clinical Research Development Unit Beheshti Hospital, Yasuj University of Medical Sciences, Yasuj, Iran

4 Instructor, Department of Pediatric Nursing, Hamadan University of Medical Sciences, Hamadan, Iran

5 Master of critical care Nursing, Clinical Research Development Unit Beheshti Hospital, Yasuj University of Medical Sciences, Yasuj, Iran
}

\author{
Correspondence: Akvan Paymard \\ Master of critical care Nursing, Clinical Research Development Unit Beheshti Hospital \\ Yasuj University of Medical Sciences, Yasuj, Iran

\section{E-mail: Akvan_paimard9@yahoo.com}

Received: 17 Jan 2018, Accepted: 15 Feb 2018

(C) 2018 by the authors; licensee Modestum Ltd., UK. This article is an open access article distributed under the terms and conditions of the Creative Commons Attribution License (http://creativecommons.org/licenses/by/4.0/). 
high share in livestock breeding, can be among the cases of exposure to brucellosis. The brucellosis fever can be transmitted through conjunctiva, scratches, excreta, contaminated tissues, and through the respiratory system to humans [13]. Human transmission to humans is rare (14). The brucellosis mosquito course has been reported for one to three weeks (15). And with symptoms such as sudden shivering, pain, weight loss, headache, loss of appetite and excessive sweating (16). For diagnosis of brucellosis, bacteriological, serological and internal tests are used (17). Brucellosis disease control depends on its agent control (animals) (18). Lack of information, credit, and lack of access to resources can increase the process of control and treatment of brucellosis, which requires intergenerational collaboration (19). An increase in the prevalence and incidence of brucellosis can have irreparable consequences for the health system of the country (20). Lack of control of livestock and poultry keeping. Also, lack of adequate supervision of products derived from them, such as dairy and edible tissues, can generally disrupt the community (21). Regarding the importance and status of the subject, the present study aimed to determine the rate and causes of brucellosis in Kohgiluyeh and Boyer Ahmad province in 2017.

\section{MATERIALS AND METHODS}

The present study was a descriptive-analytic study with the aim of determining the rate and causes of brucellosis in Kohgiluyeh and Boyer Ahmad Province during the period of April-2015. Sampling was done by census and the study population included 300 patients with brucellosis. After obtaining the necessary permissions from the authorities and receiving the code of ethics, the necessary information was obtained through the examination of the file of patients with brucellosis. Information was extracted from the checklist of the case and information about the patients. After completing the data, descriptive statistics methods were used to analyze and analyze.

\section{FINDINGS}

The mean age of the patients was 39 years. According to the results obtained in 2005, 2006, and 1392, only one case of brucellosis was reported. Of the 300 patients with brucellosis, the number of cases had 17 negative tests. The highest number of occurrences in 1395 was 143 cases and the highest occurrence was 171 in the spring. Boyer Ahmad city has the highest rate with 107 cases and Bahmei city with the least amount of brucellosis in 9 cases. 360 people were from rural population. The livestock jobs with the highest 147 cases and the military occupation with the least number of cases were the lowest. There were 182 patients with a history of previous brucellosis. There were 294 cases of predisposed livestock contacts. Of the number of affected people, 217 were trained in livestock keeping. 282 had non-pasteurized dairy consumption (Table 1).

\section{DISCUSSION}

In the present study, the results showed that the highest incidence was male, a study by Taheri Sudoujani eat all in Shahre-kord showed that men had a higher rate of infection due to the higher exposure of men to the affected livestock (8). The mean age of the patients was 39 years, which was consistent with the results of the research. Dehnavi et al., The age status of the individuals indicate that the age group is more likely to have fever than the other age groups due to their high performance and activity. Malta (22).

Some people have had a negative result after testing, which is consistent with the results of Mostafavi et al. (23), livestock care and seasonal conditions can also affect the brucellosis. Based on the results, the rate of brucellosis on the basis of risk has increased that the results Soleimani et al and Mohammedan et al were similar $(24,25)$, increase the rate of brucellosis in Kohgiluyeh Boyer Ahmad can be caused by the low awareness and lack of proper treatment of animals, lack of coverage of immunization of animals and the consumption of contaminated factor. Also, the distribution of the rate of brucellosis in different cities confirms this trend. People living in the village had the highest rates, which is the result of Hamzuy et al. (26), because of the greater exposure of the rural population to the livestock of this group is more likely to be exposed than urban populations. Farmers were more likely to suffer from brucellosis than the rest of the population. Ehrat et al. Found that the largest group of brucellosis was the livestock population, which confirms the result, the more people have more direct contact with animals and livestock. Prolonged to have a brucellosis (27). While the highest number of people with a history of family history of fever did not have this, Royan et al. (28) found this to be the case. Of course, a history of heart disease can have a greater impact on the development of the next. People who had milk had the highest levels of infection, Mousavi and colleagues concluded in their study that most people with brucellosis had higher milk intake than dairy products (29), milk as an important The most important source of animal 
Table 1: Number of people affected by the table based on different variables

\begin{tabular}{|c|c|c|}
\hline \multicolumn{2}{|c|}{ Variable } & \multirow{2}{*}{$\begin{array}{c}\text { Number } \\
68\end{array}$} \\
\hline \multirow{4}{*}{ Year } & 2017 & \\
\hline & 2016 & 143 \\
\hline & 2015 & 14 \\
\hline & 2014 & 18 \\
\hline \multirow{4}{*}{ Season } & Spring & 71 \\
\hline & Summer & 94 \\
\hline & Fall & 59 \\
\hline & Winter & 57 \\
\hline \multirow{7}{*}{ City } & Basht & 13 \\
\hline & Bahmei & 9 \\
\hline & Boyer Ahmad & 107 \\
\hline & Dena & 36 \\
\hline & Kohgiluyeh & 12 \\
\hline & Gach-saran & 89 \\
\hline & & 31 \\
\hline \multirow{2}{*}{ Location } & Urban & 32 \\
\hline & Rural & 360 \\
\hline \multirow{3}{*}{ Dairy consumption } & Lion & 264 \\
\hline & Butter, colostrum and milk head & 8 \\
\hline & Cheese & 28 \\
\hline \multirow{3}{*}{ Family history } & No previous history & 182 \\
\hline & With previous history & 55 \\
\hline & Unknown record & - \\
\hline \multirow{8}{*}{ Group } & Housewife & 100 \\
\hline & Child & 15 \\
\hline & Student & 18 \\
\hline & Manual worker & 9 \\
\hline & Animal husbandry & 147 \\
\hline & Student & 2 \\
\hline & Free & 7 \\
\hline & Military & 1 \\
\hline
\end{tabular}

dairy and, on the other hand, due to its high consumption, can cause the spread of brucellosis more than other dairy groups, which is not enough attention to harvest control and how it is produced and consumed.

\section{CONCLUSION}

Given the nature of Kohgiluyeh and Boyer Ahmad province and the existence of livestock and dairy production, as well as the high consumption of livestock and dairy products in the province, since it is possible that the infection with brucellosis is high in such a situation, it is better to have the necessary training programs General and specific at different levels of prevention for different classes of society.

\section{REFERENCES}

1. Mirnejad R, Jazi FM, Mostafaei S, Sedighi M. Molecular investigation of virulence factors of Brucella melitensis and Brucella abortus strains isolated from clinical and non-clinical samples. Microbial Pathogenesis. 2017;109:814. https://doi.org/10.1016/j.micpath.2017.05.019

2. Jia B, Zhang F, Pang P, Zhang T, Zheng R, Zhang W, et al. Brucella endocarditis: Clinical features and treatment outcomes of 10 cases from Xinjiang, China. Journal of Infection. 2017;74(5):512-4. https://doi.org/10.1016/j.jinf.2017.01.011

3. Acharya KP, Kaphle K, Shrestha K, Bastuji BG, Smits HL. Review of brucellosis in Nepal. International Journal of Veterinary Science and Medicine. 2016.

4. Araj GF. Human Brucellosis and Its Complications. Neurobrucellosis: Springer; 2016. p. 7-12.

5. Kumar VN, Bharathi MV, Porteen K, Sarath T, Sekar M. Prevalence of Brucella Antibodies in Milk from Different Districts of Tamil Nadu. 2016.

6. Arenas N, Moreno V. Economic impact of Brucella abortus infection in cattle from the Sumapaz region, Colombia. Revista de la Facultad de Medicina Veterinaria y de Zootecnia. 2016;63(3):218-28. 
7. Kaboutari J, Sharifi H, Yousefzade A, Mashayekhi Kh, Kroshkam M, Afshari Pour N. Seroprevalence of ovine and caprine anti-brucella antibodies in south of Kerman province (Iran, 2012). Journal of Veterinary Research. 2016;70(4):371-5.

8. Taheri soodejani $\mathrm{m}$, lotfi $\mathrm{m}$, ghaderi a, reisi a, mohannadzadeh $\mathrm{m}$. Epidemiology of brucellosis in Shahr-e- Kord during the years 2010 to 2014. Pars of Jahrom University of Medical Sciences. 2016;14(1):1-7.

9. Al Shehhi N, Aziz F, Al Hosani F, Aden B, Blair I. Human brucellosis in the Emirate of Abu Dhabi, United Arab Emirates, 2010-2015. BMC infectious diseases. 2016;16(1):558. https://doi.org/10.1186/s12879-016-1900-9

10. Tsegay A, Tuli G, Kassa T, Kebede N. Seroprevalence and risk factors of brucellosis in abattoir workers at Debre Zeit and Modjo export abattoir, Central Ethiopia. BMC infectious diseases. 2017;17(1):101. https://doi.org/10.1186/s12879-017-2208-0

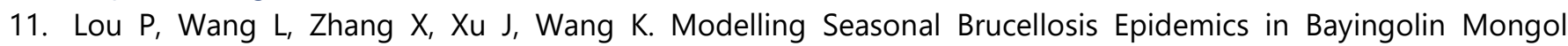
Autonomous Prefecture of Xinjiang, China, 2010-2014. BioMed research international. 2016;2016.

12. Moosazadeh M, Nikaeen R, Abedi G, Kheradmand M, Safiri S. Epidemiological and Clinical Features of People with Malta Fever in Iran: A Systematic Review and Meta-Analysis. Osong public health and research perspectives. 2016;7(3):157-67. https://doi.org/10.1016/j.phrp.2016.04.009

13. Oliveira MS, Dorneles EMS, Soares PMF, Fonseca AA, Orzil L, de Souza PG, et al. Molecular epidemiology of Brucella abortus isolated from cattle in Brazil, 2009-2013. Acta tropica. 2017;166:106-13. https://doi.org/10.1016/j.actatropica.2016.10.023

14. Wang X, Li Z, Li B, Chi H, Li J, Fan H, et al. Bioluminescence Imaging of Colonization and Clearance Dynamics of Brucella Suis. Molecular Imaging and Biology. 2016;18(4):519-26. https://doi.org/10.1007/s11307-015-0925-6

15. Hu Y, Coates AR. Pharmaceutical composition for treating a microbial infection. Google Patents; 2017.

16. Sampson E. Awareness, knowledge and practices of workers in two community abattoirs (Longdenville and Chaguanas) in their interaction with Brucellosis positive cattle and water buffalo. 2016.

17. Godfroid J, Beckmen K, Helena Nymo I. Removal of Lipid from Serum Increases Coherence between Brucellosis Rapid Agglutination Test and Enzyme-linked Immunosorbent Assay in Bears in Alaska, USA. Journal of wildlife diseases. 2016;52(4):912-5. https://doi.org/10.7589/2015-11-298

18. Ficht TA, Ficht AR, Tsolis R, Adams LG. Controlled release vaccines and methods for treating Brucella diseases and disorders. Google Patents; 2016.

19. Gadaga B, Etter E, Mukamuri B, Makwangudze K, Pfukenyi D, Matope G. Living at the edge of an interface area in Zimbabwe: cattle owners, commodity chain and health workers' awareness, perceptions and practices on zoonoses. BMC public health. 2016;16(1):84. https://doi.org/10.1186/s12889-016-2744-3

20. Angara T, Ismael A, Ibrahim A, Osman S. Assessment of the economic losses due to bovine brucellosis in Khartoum State, Sudan. International Journal of Technical Research and Applications. 2016;4(2):85-90.

21. He M, Wang J, Chen L, Liu J, Zeng P. The Impact of Emerging Infectious Diseases on Chinese Blood Safety. Transfusion medicine reviews. 2017;31(2):94-101. https://doi.org/10.1016/j.tmrv.2016.10.002

22. Dehnavi S SN, Zare S. Demoraphic characteristics,linical sings \&labratoary findings in Brycellosis hospitalized pations In kermanshah. J Clin Res Paramed Sci. 2014;3(4):216-22.

23. Mostafavi E, Asmand M. Trend of Brucellosis in Iran from 1991 to 2008. irje. 2012; 8 (1) :94-101.

24. Soleymani A AS, Seyf $M$, et al. Descriptive epidemiology of brucellosis in the province from the year 2005 to 2008. Tabriz J. 2012;3(4):64-9.

25. Mohammadian M M-H. A. Epidemiological Characteristics and Incidence Rate of Brucellosis Over A Period of 14 Years in the Tiran-Karvan Township, Isfahan. J Isfahan Med Sch. 2014;32(293).

26. Hamzavi Y KN, Ghazizadeh M. Epidemiological study of brucellosis in Kermanshah province in 2011. J Kermanshah. 2011;18(2):14-21.

27. Earhart K VS, Yarmohamedova N, et al. Risk factors for brucellosis in Samarqand Oblast, Uzbekistan. Int J Infect Dis. 2009;13(6):749-53. https://doi.org/10.1016/j.ijid.2009.02.014 
28. Roya N, Abbas B. Colorectal cancer trends in Kerman province, the largest province in Iran, with forecasting until 2016. Asian Pac J Cancer Prev 2013; 14(2): 791-3. https://doi.org/10.7314/APJCP.2013.14.2.791

29. Mousavi M SN, Mostafavi E. Epidemiological features survey of brucellosis in Gylangharb city, Kermanshah province. Zeonisis J. 2013;1(2):8-31.

$\diamond \diamond \diamond \diamond \diamond \diamond \diamond$

http://www.ejgm.co.uk 